\title{
EDITORIAL
}

\section{Epidemiological studies in hypertension: more relevant than ever}

\author{
Journal of Human Hypertension (2016) 30, 219-220; doi:10.1038/ \\ jhh.2016.2
}

Epidemiology has often been referred to as a basic science of public health and the cornerstone of public health services. ${ }^{1}$ Epidemiology has been best described by Last, ${ }^{2}$ who defined it as the study of the distribution and determinants of health-related states or events (including disease), and the application of this study to the control of diseases and other health problems. Epidemiological studies therefore, among other things, try to describe the status of a particular disease in a specified population, identify subgroups at risk, identify risk factors, identify methods of spread, progression or initiation of the disease and also help to develop models that can predict the risk of the disease and even response to treatment. They study various factors that can influence the disease process, such as ethnicity, race, age, sex and nutrition, and genetic, geographical and immunological factors to name a few. Epidemiological studies help in health planning, resource allocation, targeting groups for health education and disease prevention. ${ }^{1}$ Epidemiology also helps researchers and statisticians to generate sample sizes for their studies by providing incidence and prevalence data and normal reference values.

The word 'epidemiology' however tends to conjure up images of numbers and complex statistics in the minds of clinicians who accept its importance, but do not really appear to be interested in this field. ${ }^{3}$ Interestingly, although epidemiology deals with populations rather than individuals, clinicians use data from epidemiological studies in their day-to-day clinical practice for decision making on individual patients. When we ask patients to stop smoking or take more exercise, our advice is based on the findings of epidemiological studies. Epidemiology gives us the information that we need to understand the disease process and the underlying causes that might be prevalent in that geographical area, and also help us also identify disease-modifying factors such as dietary and cultural factors that have a role in the pathogenesis of that disease in that location.

This is especially true for a non-communicable chronic disease such as hypertension. Knowledge of the demographics, the distribution of the disease, the common risk factors in a particular geographic area or ethnic group and other social and cultural issues will help us plan strategies better. ${ }^{4,5}$ Treatment can be tailored better based on the particular dietary habits and cultural practices in that area. If studies show that hypertension is being identified at an earlier age, it could help us to device more health screening in high schools and colleges and improve the health education we give our younger population.

Epidemiological studies also help us understand the changing prevalence of hypertension over the years in different countries. ${ }^{6}$ The incidence of hypertension appears to have stabilised in some countries, ${ }^{7}$ although it appears to be increasing in others, ${ }^{8}$ and also appears to be manifesting itself at a younger age. ${ }^{9}$ There might, however, be a reporting bias here, as patients in developing countries now have better access to health care and so the disease is being identified more often, rather than there being a definite increase in the incidence of the disease. ${ }^{9}$
Bearing in mind the importance of epidemiological studies in hypertension, this special issue of the Journal of Human Hypertension has been devoted entirely to epidemiological studies. We have papers from China, ${ }^{10,11}$ Guinea, ${ }^{12}$ Bangladesh, ${ }^{13}$ Iran, ${ }^{14}$ Canada, ${ }^{15}$ South Africa ${ }^{16}$ and Nigeria. ${ }^{17}$ Interestingly, there are still new data being published from populations that have previously not been studied. One would have expected that, in this highly connected modern world, there are no places left on the planet that do not have proper health statistics. However, now with an increasing access to remote areas, we are getting more data on places that previously were off the health maps, which is good news to the public health specialists. The bad news, however, is that these previously neglected areas appear to have a high prevalence of hypertension; both rural Bangladesh and the urban slum in Nigeria report a very high incidence of $40 \%$ and $52 \%$, respectively. ${ }^{13,17}$ Being out of the radar of public health services for so long, it is likely that these areas had low input in terms of health education, prevention and treatment and thereby poor health indices.

Epidemiological studies are not just about incidences and prevalence. They also help us determine what is considered 'normal' for a particular region. This is highlighted by another article that is published in this issue of the journal from Ataei et $a .^{1}{ }^{18}$ where they publish for the first time reference percentiles for blood pressure by age, sex and height for children and adolescents in Iran. This is an important paper, as it used data from nearly 17000 children over a 10-year period to construct this chart. Most countries, especially in the developing world, tend to use reference limits taken from developed western countries that have different ethnicity, race and geographical features, all of which can individually affect blood pressure. This paper shows us that, although it might be practically difficult to implement, all countries should ideally use locally derived reference data, especially for children and adolescents.

Studying disease patterns in small ethnic groups, such as the indigenous population in Canada, ${ }^{15}$ or specific age groups, such as adolescents in South Africa, ${ }^{16}$ also gives us important information showing that each ethnic group or each age group is unique and has to be dealt with differently.

The aims of modern-day epidemiology has perhaps not changed much since the time of John Snow, who is often called the 'father of modern epidemiology' for his pioneering work on describing the spread of cholera in a suburb of London in the Nineteenth century. We still seek to find the cause of diseases, their spread and means to control them. For hypertension in particular, we need to know how the prevalence is changing, whether new groups are at risk (younger age, indigenous populations and so on), whether health education is effective and reaching the groups it is targeted at and whether we need to do anything more from a public health point of view. There is a changing lifestyle among all populations that are consuming more calories but becoming more sedentary at the same time. We need to know whether normal reference values that were developed some time ago are still valid and need updating. This is where epidemiological studies help us. Epidemiological studies in hypertension therefore are more relevant now than ever, and not just for the public health services but for every day clinical practice. 


\section{CONFLICT OF INTEREST}

The author declares no conflict of interest.

SK Nadar

Sultan Qaboos University Hospital, Muscat, Oman E-mail: sunilnadar@gmail.com

\section{REFERENCES}

1 Sackett DL, Haynes RB, Guyatt GH, Tugwell P. Clinical Epidemiology: a Basic Science for Clinical Medicine. Little Brown: Boston, MA, USA, 1985.

2 Last JM. A Definition of Epidemiology, 4th edn. Oxford University Press: New York, NY, USA, 2001.

3 Shyam C. Epidemiology through the eyes of clinicians. Int J Epidemiol 2003; 32(6): 1113-1114.

4 Shiue I. Self and environmental exposures to drinking, smoking, gambling or video game addiction are associated with adult hypertension, heart and cerebrovascular diseases, allergy, self-rated health and happiness: Japanese General Social Survey, 2010. Int J Cardiol 2015; 181: 403-412.

5 Shiue I, Hristova K. Associated social factors of hypertension in adults and the very old: UK Understanding Society cohort, 2009-2010. Int J Cardiol 2013; 168(4): 4563-4565.

6 Nadar S, Lip GY. Secular trends in cardiovascular disease. $J$ Hum Hypertens 2002; 16(10): 663-666.

$7 \mathrm{Kim}$ NR, Kim HC. Prevalence and trends of isolated systolic hypertension among Korean adults: the Korea National Health and Nutrition Examination Survey, 1998-2012. Korean Circ J 2015; 45(6): 492-499.

8 Linhart C, Tukana I, Lin S, Taylor R, Morrell S, Vatucawaqa P et al. Continued increases in hypertension over three decades in Fiji, and the influence of obesity. J Hypertens 2016; 34(3): 402-409.
9 Whelton PK, He J, Muntner P. Prevalence, awareness, treatment and control of hypertension in North America, North Africa and Asia. J Hum Hypertens 2004; 18 (8): 545-551.

10 Li T, Xian Y, Mao H-M, Jiang W-J, Zhang L, Chow EPF et al. Prevalence, awareness, treatment and control of high blood pressure among Chinese rural population in Haimen, Jiangsu. J Hum Hypertens 2016; 30: 225-230.

11 Zhou Y, Qian Z, Vaughn MG, Boutwel BB, Yang M, Zeng X-W et al. Epidemiology of elevated blood pressure and associated risk factors in Chinese children: the SNEC study. J Hum Hypertens 2016; 30: 231-236.

12 Camara A, Baldé NM, Diakité M, Sylla D, Baldé EH, Kengne AP et al. High prevalence, low awareness, treatment and control rates of hypertension in Guinea: results from a population-based STEPS survey. J Hum Hypertens 2016; 30: 237-244

13 Islam FMA, Bhuiyan A, Chakrabarti R, Rahman MA, Kanagasingam Y, Hiller JE. Undiagnosed hypertension in a rural district in Bangladesh: the Bangladesh Population-based Diabetes and Eye Study (BPDES). J Hum Hypertens 2016; 30: 252-259.

14 Sepanlou SG, Sharafkhah M, Poustchi H, Malekzadeh MM, Etemadi A, Khademi H et al. Hypertension and mortality in the Golestan Cohort Study: A prospective study of 50000 adults in Iran. J Hum Hypertens 2016; 30: 260-267.

15 Foulds HJA, Bredin SSD, Warburton DER. The vascular health status of a population of adult Canadian Indigenous peoples from British Columbia. $J$ Hum Hypertens 2016; 30: 278-284.

16 Awotidebe A, Monyeki MA, Moss SJ, Strydom GL, Amstrong M, Kemper HCG. Relationship of adiposity and cardiorespiratory fitness with resting blood pressure of South African adolescents: the PAHL Study. J Hum Hypertens 2016; 30: 245-251.

17 Ezeala-Adikaibe BA, Orjioke C, Ekenze OS, Ijoma U, Onodugo O, Okudo G et al. Population-based prevalence of high blood pressure among adults in an urban slum in Enugu, South East Nigeria. J Hum Hypertens 2016; 30: 285-291.

18 Ataei A, Hosseini M, Fayaz M, Navidi I, Taghiloo A, Kalantari K et al. Blood pressure percentiles by age and height for children and adolescents in Tehran, Iran. J Hum Hypertens 2016; 30: 268-277. 